Pacific Journal of Mathematics

DETERMINATION OF BOUNDS SIMILAR TO THE LEBESGUE 


\title{
DETERMINATION OF BOUNDS SIMILAR TO THE LEBESGUE CONSTANTS
}

\author{
H. P. Dikshit AND A. KumaR
}

Bounds for the Nörlund transformation of a sequence associated with Fourier series are determined. These are applied to obtain a necessary and sufficient condition for the convergence of the Nörlund transformation of Fourier series when the generating function satisfies a condition lighter than the continuity requirement.

1. Introduction. It is well known that the unboundedness of Lebesgue constants implies the existence of a function whose Fourier series diverges at a point of continuity (e.g., see [5], §6). Considering a class of transformed sequences of Fourier series at a point at which the generating function satisfies a lighter assumption than the continuity, we first obtain bounds for the sequence. An interesting application of such a result gives a necessary and sufficient condition for the convergence of the transformed sequence.

In the present paper, we consider the Nörlund transformation $\left(N, p_{n}\right)$ associated with a given sequence of numbers $\left\{p_{n}\right\}$ such that $P_{n}=\sum_{k=0}^{n} p_{k} \neq 0$ and $p_{-1}=0$. The $\left(N, p_{n}\right)$ transformation of a series $a=\sum_{k=0}^{\infty} a_{k}$ or the sequence of its partial sums $\left\{s_{n}\right\}$, is defined by the sequence $\left\{t_{n}(a)\right\}$ where

$$
t_{n}(a)=\sum_{k=0}^{n} P_{n-k} a_{k} / P_{n}=\sum_{k=0}^{n} p_{n-k} s_{k} / P_{n} .
$$

Suppose $f(t)$ is a periodic function with period $2 \pi$ and $f(t) \epsilon$ $L(0,2 \pi)$. Let $F=\sum_{n=1}^{\infty} A_{n}(x)$ denotes the Fourier series of $f(t)$, at $t=x$. We introduce the following notations for convenience. For a given number $s$

$$
\begin{aligned}
& \varphi(t)=f(x+t)+f(x-t)-2 s ; t \varphi_{1}(t)=\int_{0}^{t} \varphi(u) d u, \\
& \Delta_{n} s_{n}=\Delta s_{n}=s_{n}-s_{n+1}, \Delta^{2} s_{n}=\Delta\left(\Delta s_{n}\right) ; R_{n}=n p_{n} / P_{n} ; \\
& P_{n} V_{n}(r)=n^{r-1} \sum_{k=1}^{n} k\left|\Delta^{r} p_{k-r}\right| ; P_{n} S_{n}(r)=n^{r-1} \sum_{k=1}^{n} P_{k} k^{-r},
\end{aligned}
$$

where $r=1,2$.

For sequences $\left\{a_{n}\right\}$ and $\left\{b_{n}\right\}, a_{n} \asymp b_{n}$ means that $a_{n}$ lies between two positive constant multiples of $b_{n}$.

$K$ denotes a positive constant not necessarily the same at each occurrence and $[x]$ denotes the greatest integer not greater than $x$, in particular $w=[1 / t]$. For any sequence $\left\{a_{n}\right\}, a(x)=a_{[x]}$. 
2. The main results. The following theorem which provides bounds of Lebesgue constants for Nörlund method is essentially due to Hille and Tamarkin ([4], Theorem 7).

THEOREM A. Suppose that $\left\{p_{n}\right\}$ is a positive sequence such that $\left\{V_{n}(1)\right\} \in B$, i.e., $\left\{V_{n}(1)\right\}$ is a bounded sequence, then

$$
\int_{0}^{\pi}|N(n, t)| d t \asymp S_{n}(1),
$$

where $\{N(n, t)\}$ is the sequence of $\left(N, p_{n}\right)$ transformation of $1 / 2+$ $\sum_{k=1}^{\infty} \cos k t$.

The original version of Theorem A as given in [4] contains the additional hypotheses that $\left\{R_{n}\right\} \in B$ and $\left(N, p_{n}\right)$ is regular. However, we observe that

$$
n p_{n}=-\sum_{k=0}^{n-1} \Delta\left(k p_{k}\right)=P_{n-1}-\sum_{k=1}^{n} k\left(\Delta p_{k-1}\right)
$$

and, therefore, $\left\{V_{n}(1)\right\} \in B$ implies $\left\{R_{n}\right\} \in B$ and the latter implies that $\left(N, p_{n}\right)$ is regular.

As an interesting application of (2.1), Hille and Tamarkin ([4], Theorem II) proved the following result.

THEOREM B. Suppose that $p_{n}>0,\left\{V_{n}(1)\right\} \in B$. Then in order that the Fourier series $F$ should be summable $\left(N, p_{n}\right)$ to $s$ whenever $\varphi(t)=o(1)$ as $t \rightarrow 0$, it is necessary and sufficient that $\left\{S_{n}(1)\right\} \in B$.

Under a less restrictive condition on $f(t)$ viz., $\varphi_{1}(t)=o(1), t \rightarrow 0$, Astrachan ([1], Theorem I; see also Dikshit [3]) has obtained only a set of sufficient conditions for the $\left(N, p_{n}\right)$ summability of the series $F$.

In the present paper, we first prove the following and then deduce a necessary and sufficient condition for the $\left(N, p_{n}\right)$ summability of the series $F$ under the assumption: $\varphi_{1}(t)=o(1), t \rightarrow 0$.

THEOREM 1. Suppose that $\left\{p_{n}\right\}$ is a positive sequence such that $\left\{V_{n}(2)\right\} \in B$, then

$$
\int_{0}^{\pi}|M(n, t)| d t \asymp S_{n}(2),
$$

where $\{M(n, t)\}$ is the $\left(N, p_{n}\right)$ transformation of $\{k \cos k t\}$.

Using the result (2.3), we shall prove the following:

THEOREM 2. Suppose that $\left\{p_{n}\right\}$ satisfies the hypotheses of Theorem 1. Then in order that the Fourier series $F$ should be summable 
$\left(N, p_{n}\right)$ to $s$ whenever $\varphi_{1}(t)=o(1), t \rightarrow 0$ it is necessary and sufficient that $\left\{S_{n}(2)\right\} \in B$.

3. Preliminary results. We use the following lemmas for the proof of our theorems.

LEMMA 1. Let $\left\{a_{n}\right\}$ be a given sequence, then for any $x \neq 1$, we have

$$
\begin{gathered}
\sum_{k=r}^{s} a_{k} x^{k}=x(1-x)^{-2}\left\{\sum_{k=r}^{s-2}\left(\Delta^{2} a_{k}\right)\left(x^{k+1}-x^{r}\right)+\left(\Delta a_{s-1}\right)\left(x^{s}-x^{r}\right)\right\} \\
+(1-x)^{-1}\left(a_{r} x^{r}-a_{s} x^{s+1}\right)
\end{gathered}
$$

where $r$ and $s$ are integers such that $s-2 \geqq r \geqq 0$.

The proof of Lemma 1 is direct.

LEMMA 2. Suppose a sequence $\left\{s_{n}\right\}$ satisfies the conditions:

$$
\sum_{k=1}^{n}\left|s_{k}\right| \leqq K T_{n} \text { and } \sum_{k=1}^{n} k^{2}\left|\Delta^{2} s_{k-2}\right| \leqq K T_{n}
$$

for some sequence of positive numbers $\left\{T_{n}\right\}$. Then

$$
\sum_{k=1}^{n} k\left|\Delta s_{k-1}\right| \leqq K T_{n}
$$

Lemma 2 is a particular case of a more general result given in ([3], Lemma 1).

LEMMA 3. If $\left\{p_{n}\right\}$ is a nonnegative sequence and $\left\{V_{n}(2)\right\} \in B$, then (i) $\left\{V_{n}(1)\right\} \in B$, and (ii) $n=0\left(P_{n}\right)$.

Proof. It follows trivially from the assumption $\left\{V_{n}(2)\right\} \in B$ that

$$
\sum_{k=1}^{n} k^{2}\left|\Delta^{2} p_{k-2}\right|=0\left(\left|P_{n}\right|\right)
$$

and (i) therefore follows from Lemma 2.

In order to show (ii), we observe that if, for any $k, \Delta^{2} p_{k-2} \neq 0$ then, for all sufficiently large $n, K P_{n} \geqq n$. Otherwise, if $\Delta^{2} p_{k-2}=0$ for all $k \geqq 1$, then $\Delta p_{k-2}$ is a constant which is obtained by putting $k=1$. Thus, $K P_{n} \geqq-\sum_{k=1}^{n+1} \Delta p_{k-2}=(n+1) p_{0}$ and (ii) follows.

The next lemma follows from a result due to Hille and Tamarkin ([4], Lemma 9) when we observe that $\left\{V_{n}(1)\right\} \in B$ implies that $\left\{R_{n}\right\} \in B$.

LEMMA 4. If $\left\{p_{n}\right\}$ is a positive sequence and $\left\{V_{n}(1)\right\} \in B$, then $0<\varepsilon \leqq v / u \leqq 1 / \varepsilon$ implies the existence of an a such that $0<a \leqq$ $P(v) / P(u) \leqq 1 / a$. 
LemMA 5. If $\left\{p_{n}\right\}$ is a positive sequence and $\left\{V_{n}(1)\right\} \in B$, then for any positive $\delta \leqq \pi$,

$$
\int_{1 / n}^{\delta} t^{-1}\left|\sum_{k=w+1}^{n} p_{k} \exp i k t\right| d t=0\left(P_{n}\right)
$$

The proof of Lemma 5 is essentially included in ([4], see (6.07) and Lemma 7 with $m=2,3$ or 4 for which the condition: $\left\{S_{n}(1)\right\} \in B$ is not used).

4. Proof of Theorem 1. We first write

$$
\begin{aligned}
P_{n} M(n, t) & =\sum_{k=0}^{w-1} p_{k}(n-k) \cos (n-k) t+\operatorname{Re} \sum_{k=w}^{n} p_{k}(n-k) \exp i(n-k) t \\
& =\sum_{1}+\operatorname{Re} \sum_{2},
\end{aligned}
$$

say. Applying Lemma 1 to $\sum_{2}$, we obtain

$$
\sum_{2}=(1-\exp (-i t))^{-1} p_{w}(n-w) \exp i(n-w) t-X(n, t)
$$

where

$$
|X(n, t)| \leqq K t^{-2}\left\{p_{n-1}+\sum_{k=w}^{n-2}\left|\Delta_{k}^{2}\left(p_{k}(n-k)\right)\right|\right\} .
$$

Thus, we have

$$
P_{n} M(n, t)=\sum_{1}+\sum_{3}-\operatorname{Re} X(n, t),
$$

where $\sum_{3}=p_{w}(n-w) \sin (n-w+1 / 2) t /\{2 \sin t / 2\}$.

We now introduce the intervals $I_{r}=((2 r+1 / 3) \pi / n,(2 r+4 / 9) \pi / n)$ for $r=1,2, \cdots,[n / 4 \pi]-1$, which are all disjoint subintervals of $(2 / n, 1)$. Considering $\sum_{1}$, we observe that the restriction $0 \leqq k<w$ implies $0 \leqq k t<1$ for all $t \in(2 / n, 1)$, so that whenever $t \in I_{r}$, $(n-k) t \in J_{r}=((2 r+1 / 3) \pi-1,(2 r+4 / 9) \pi)$. Thus, for $t \in I_{r}, \cos (n-k) t$ is not less than $\cos (4 \pi / 9)$. We also see that for $t \in(2 / n, 1 / 2)$, $0<t(w-1 / 2)<1$ and, therefore, $(n-w+1 / 2) t \in J_{r}$ whenever $t \in I_{r}$. Thus $\sin (n-w+1 / 2) t$ is not less than $\sin (\pi / 3-1)=2 C_{0}$, say. In view of these observations, if we write $E=U I_{r}$ and $Y_{n}=\int_{1 / n}^{\pi}|X(n, t)| d t$, where $n$ is sufficiently large, then

$$
\begin{aligned}
P_{n} \int_{1 / n}^{\pi} \mid & M(n, t)\left|d t+Y_{n} \geqq \int_{2 / n}^{1 / 2}\right| \sum_{1}+\sum_{3} \mid d t \\
& \geqq 2 C_{0} \int_{E}\left\{\sum_{k=0}^{w-1} p_{k}(n-k)+p_{w}(n-w)\left(2 \sin \frac{1}{2} t\right)^{-1}\right\} d t \\
& >C_{0} n \int_{E}\left\{\sum_{k=0}^{w} p_{k}\right\} d t=C_{0} n \int_{E} P(1 / t) d t
\end{aligned}
$$


since for $t \in E \subset(2 / n, 1 / 2), n-w>n / 2$.

Writing $d=\pi / 9 n$, we observe that each interval $I_{r}$ is of length $d$ and any two consecutive intervals $I_{r}, I_{r+1}$ are separated by a distance $17 d$. Now we move the intervals $I_{r}$ to the left by taking $s=t-17(r-1) d$ so that all the intervals $I_{r}$ abut upon each other. Suppose the shifted interval $I_{r}$ is denoted by $I_{r}^{*}$, then we see that for $s \in I_{r}^{*}$ and $t \in I_{r} \quad 18 s \geqq t$ so that $P(1 / t) \geqq P(1 / 18 s)$ and $P(1 / t) \geqq$ $c^{\prime} P(7 \pi / 3 s)$ for some $c^{\prime}>0$, by virtue of Lemma 4 . Thus, we have from (4.3)

$$
\begin{aligned}
P_{n} \int_{1 / n}^{\pi}|M(n, t)| d t+Y_{n} & \geqq C_{0} c^{\prime} n \int_{7 \pi / 3 n}^{7 \pi / 3 b_{n}} P(7 \pi / 3 s) d s \\
& \geqq c^{\prime \prime} n \int_{b_{n}}^{n} u^{-2} P(u) d u \geqq c P_{n} S_{n}(2),
\end{aligned}
$$

where $b_{n} \rightarrow 14 \pi / 3$ as $n \rightarrow \infty$, and $c, c^{\prime}, c^{\prime \prime}$ are some positive constants.

In order to obtain the lower bound in (2.3), we assume for the moment that for some fixed $K$,

$$
Y_{n}=\int_{1 / n}^{\pi}|X(n, t)| d t \leqq K P_{n}
$$

and deal with the cases $S_{n}(2) \geqq 2 K / c$ and $S_{n}(2)<2 K / c$ separately. In the former case, (4.5) gives that $Y_{n} \leqq(1 / 2) c P_{n} S_{n}(2)$ so that we have from (4.4),

$$
\int_{1 / n}^{\pi}|M(n, t)| d t \geqq \frac{1}{2} c S_{n}(2) .
$$

For the other case, we first observe that if $t \leqq \pi / 3 n$, then for all $k$ with $0 \leqq k \leqq n, \cos k t \geqq 1 / 2$. Hence under the hypothesis: that $p_{n}>0$, we have

$$
\begin{aligned}
& \int_{0}^{\pi}|M(n, t)| d t>\int_{0}^{\pi / 3 n}|M(n, t)| d t \\
& \quad \geqq \frac{1}{2} \frac{\pi}{3 n} \frac{1}{P_{n}} \sum_{k=1}^{n} k p_{n-k} \geqq \frac{\pi}{12 P_{n}} \sum_{k=r(n)}^{n} p_{n-k}
\end{aligned}
$$

where $2 r(n)=n$ or $n+1$ according as $n$ is even or odd. Now using Lemmas 3 and 4 , we have

$$
\int_{0}^{\pi}|M(n, t)| d t \geqq \pi P\left(\frac{n-1}{2}\right) / 12 P_{n} \geqq c^{*},
$$

where $c^{*}$ is some positive constant. Thus, in view of the condition $S_{n}(2)<2 K / c$, we have

$$
\int_{0}^{\pi}|M(n, t)| d t>\left(c c^{*} / 2 K\right) S_{n}(2) .
$$


In view of (4.6) and (4.7), we have in either case

$$
\int_{0}^{\pi}|M(n, t)| d t \geqq A S_{n}(2)
$$

where $A=\min \left(c / 2, c c^{*} / 2 K\right)$.

We now complete the proof of the lower bound in (2.3) by showing (4.5). Substituting $t^{-1}=u$ in (4.5) and observing that

$$
\left\{\Delta_{k}^{2}(n-k) p_{k}\right\}=(n-k-2) \Delta^{2} p_{k}+2 \Delta p_{k},
$$

we have

$$
\int_{1 / n}^{\pi}|X(n, t)| d t \leqq K n p_{n-1}+K L(n)
$$

where

$$
L(n)=\int_{1 / \pi}^{n} \sum_{k=[u]}^{n}\left\{(n-k)\left|\Delta^{2} p_{k-2}\right|+\left|\Delta p_{k-2}\right|\right\} d u .
$$

But

$$
\begin{aligned}
L(n) & \leqq K n \sum_{r=1}^{n} \sum_{k=r}^{n}\left|\Delta^{2} p_{k-2}\right|+K \sum_{r=1}^{n} \sum_{k=r}^{n}\left|\Delta p_{k-2}\right|+K n p_{0} \\
& =K n \sum_{k=1}^{n} k\left|\Delta^{2} p_{k-2}\right|+K \sum_{k=1}^{n} k\left|\Delta p_{k-2}\right|+K n \leqq K P_{n},
\end{aligned}
$$

by virtue of the hypothesis $\left\{V_{n}(2)\right\} \in B$ and Lemma 3 . Combining (4.9) and (4.10), we prove (4.5), when we observe that $\left\{R_{n}\right\} \in B$ by Lemma 3.

It follows from the proof of Theorem I in ([1], pp. 551-553) that under the hypotheses of Theorem 1

$$
\int_{0}^{\pi}|M(n, t)| d t=o(1)+o\left(S_{n}(2)\right) .
$$

Writing $m=[n / 2]$ and using the hypotheses of Theorem 1 it follows from Lemmas 3 and 4 that there is a positive number $K$ such that

$$
S_{n}(2) \geqq \frac{n}{P_{n}} \sum_{k=m}^{n} \frac{P_{k}}{k^{2}} \geqq K n \sum_{k=m}^{n} \frac{1}{k^{2}} .
$$

We thus obtain (2.3) from (4.11) when we observe that the lower bound in (4.12) tends to $K$ as $n \rightarrow \infty$.

This completes the proof of Theorem 1 .

5. Proof of Theorem 2. We first observe that in view of 
Lemma 3, the hypotheses of Theorem 2, imply the regularity of the $\left(N, p_{n}\right)$ method. Thus, if $\left\{t_{n}(F)\right\}$ is the sequence of $\left(N, p_{n}\right)$ transformation of the series $F$, then

$$
\begin{aligned}
t_{n}(F)-s= & o(1)+\frac{1}{\pi P_{n}} \int_{0}^{\pi} \varphi_{1}(t) t^{-1}\left(\sum_{k=0}^{n} p_{n-k} \sin k t\right) d t \\
& -\frac{1}{\pi P_{n}} \int_{0}^{\pi} \varphi_{1}(t)\left(\sum_{k=0}^{n} p_{n-k} k \cos k t\right) d t \\
= & o(1)+T_{1}-T_{2}, \text { say } .
\end{aligned}
$$

In order to prove the necessity part, we first observe that if the Fourier series is $\left(N, p_{n}\right)$ summable whenever $\varphi_{1}(t)=o(1), t \rightarrow 0$ then it is certainly summable $\left(N, p_{n}\right)$ whenever $\varphi(t)=o(1)$. The latter implies that $\left\{S_{n}(1)\right\} \in B$, when we appeal to Lemma 2 and a result due to Hille and Tamarkin ([4], Theorem II). Further, $\left\{V_{n}(1)\right\} \in B$ by virtue of Lemma 2 and, therefore, following the proof of Theorem 1 in ([4], pp. 769-770), we see that $T_{1}=o(1)$ as $n \rightarrow \infty$, whenever $\varphi_{1}(t)=o(1), t \rightarrow 0$. Thus, the $\left(N, p_{n}\right)$ summability of $F$ to $s$ implies that as $n \rightarrow \infty$

$$
\int_{0}^{\pi} \emptyset_{1}(t) M(n, t) d t=o(1) .
$$

We now claim that a necessary condition for (5.1) is that

$$
\lim _{n \rightarrow \infty} \sup \int_{0}^{\pi}|M(n, t)| d t<\infty .
$$

Assuming that (5.2) fails, that is, that

$$
\lim _{n \rightarrow \infty} \sup \int_{0}^{\pi}|M(n, t)| d t=\infty,
$$

we construct a function $\varphi_{1}(t)$ such that (5.1) fails.

In view of the hypothesis $\left\{V_{n}(2)\right\} \in B$ and Lemma 2 , we have from (4.1)-(4.2) that

$$
\int_{z}^{\pi}|M(n, t)| d t=C(z)=O(1)
$$

for any fixed $z>0$. Taking $x_{0}(0)=\pi$, we observe that in view of $\left(5.2^{\prime}\right)$, we can find an increasing sequence of positive integers $\{n(r)\}_{r=1}^{\infty}$ and a decreasing sequence of numbers $\left\{x_{0}(r)\right\}_{r=1}^{\infty}$ such that

$$
\int_{Q_{r}}|M(n(r), t)| d t>r^{2}\left[r+C\left(x_{0}(r-1)\right)\right]
$$




$$
\int_{0}^{x_{0}(r)}|M(n(r), t)| d t<r^{-2},
$$

where $Q_{r}=\left[x_{0}(r), x_{0}(r-1)\right]$.

By choosing

$$
\varphi_{1}(t)=r^{-2} \operatorname{sgn} M(n(r), t)
$$

everywhere in $Q_{r}$ except in sufficiently small neighborhoods of $x_{0}(r), x_{0}(r-1)$ and those points of $Q_{r}$ at which $M(n(r), t)$ changes sign, it is clear that we can define $\varphi_{1}(t)$ in each $Q_{r}$ in such a way that its derivative exists and is bounded everywhere, that it vanishes at $x_{0}(r), x_{0}(r-1)$, that $\left|\varphi_{1}(t)\right| \leqq r^{-2}$, and that

$$
\int_{Q_{r}} M(n(r), t) \varphi_{1}(t) d t
$$

is arbitrary near to

$$
r^{-2} \int_{Q_{r}}|M(n(r), t)| d t .
$$

Thus using (5.4)-(5.5), we have

$$
\begin{aligned}
\mid \int_{0}^{\pi} \varphi_{1}(t) & M(n(r), t) d t \mid \\
\geqq & \left|\int_{Q_{r}} \varphi_{1}(t) M(n(r), t) d t\right|-\left|\int_{0}^{x_{0}(r)} \varphi_{1}(t) M(n(r), t) d t\right| \\
& \quad-\left|\int_{x_{0}(r-1)}^{\pi} \varphi_{1}(t) M(n(r), t) d t\right| \\
\geqq & -O\left(r^{-2}\right)+r^{-2} \int_{Q_{r}}|M(n(r), t)| d t-C\left(x_{0}(r-1)\right) \\
\geqq & -O\left(r^{-2}\right)+r .
\end{aligned}
$$

This contradicts (5.1) and hence, we have shown that (5.2) is a necessary condition for (5.1). The necessity part of Theorem 2 now follows when we appeal to Theorem 1.

For the sufficiency part of Theorem 2, reference may be made to [1] and [3].

REMARKs. A simple example of a function $\varphi_{1}(t)$ meeting the requirements of the construction given after (5.5) is a piecewise quintic polynomial function or more precisely a deficient quintic spline function. For the definition of such functions reference may be made to [2].

The authors would like to express their grateful thanks to Professor B. Kuttner of University of Birmingham for some valuable suggestions. 


\section{REFERENCES}

1. M. Astrachan, Studies in the summability of Fourier series by Nörlund means, Duke Math. J., 2 (1936), 543-568.

2. C. de Boor, A Practical Guide to Splines, Springer-Verlag, New York-HeidelbergBerlin, 1978.

3. H. P. Dikshit, Absolute total-effective $\left(N, p_{n}\right)$ means, Proc. Cambridge Phil. Soc., 69 (1971), 107-122.

4. E. Hille and J. D. Tamarkin, $O n$ the summability of Fourier series I, Trans. Amer. Math. Soc., 34 (1932), 757-783.

5. K. Ishiguro, On the summability methods of divergent series, Acad. Roy. Belg. Cl. Sci. Mem. Coll. in $8^{\circ}, 35$ (1965), 1-42.

Received March 14, 1980 and in revised form June 12, 1980.

UNIVERSITY OF JABALPUR

JABALPUR (INDIA) 



\section{PACIFIC JOURNAL OF MATHEMATICS}

EDITORS

DONALD BABBITT (Managing Editor)

University of California

Los Angeles, CA 90024

Hugo RossI

University of Utah

Salt Lake City, UT 84112

C. C. MOORE and ANDREW OGG

University of California

Berkeley, CA 94720

\section{J. DugundjI}

Department of Mathematics

University of Southern California

Los Angeles, CA 90007

R. FINN and J. MILGRAM

Stanford University

Stanford, CA 94305

\section{ASSOCIATE EDITORS}
R. ARENS
E. F. BECKENBACH
B. H. NEUManN
F. WOLF
K. YoSHIDA

\section{SUPPORTING INSTITUTIONS}

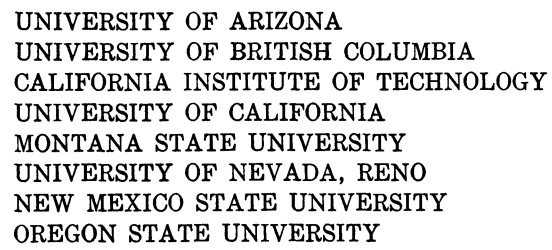

UNIVERSITY OF ARIZONA

UNIVERSITY OF BRITISH COLUMBIA

CALIFORNIA INSTITUTE OF TECHNOLOGY

UNIVERSITY OF CALIFORNIA

MONTANA STATE UNIVERSITY

UNIVERSITY OF NEVADA, RENO

NEW MEXICO STATE UNIVERSITY

OREGON STATE UNIVERSITY

\author{
UNIVERSITY OF OREGON \\ UNIVERSITY OF SOUTHERN CALIFORNIA \\ STANFORD UNIVERSITY \\ UNIVERSITY OF HAWAII \\ UNIVERSITY OF TOKYO \\ UNIVERSITY OF UTAH \\ WASHINGTON STATE UNIVERSITY \\ UNIVERSITY OF WASHINGTON
}

The Supporting Institutions listed above contribute to the cost of publication of this Journal, but they are not owners or publishers and have no responsibility for its content or policies.

Mathematical papers intended for publication in the Pacific Journal of Mathematics should be in typed form or offset-reproduced, (not dittoed), double spaced with large margins. Please do not use built up fractions in the text of the manuscript. However, you may use them in the displayed equations. Underline Greek letters in red, German in green, and script in blue. The first paragraph or two must be capable of being used separately as a synopsis of the entire paper. Please propose a heading for the odd numbered pages of less than 35 characters. Manuscripts, in triplicate, may be sent to any one of the editors. Please classify according to the scheme of Math. Reviews, Index to Vol. 39. Supply name and address of author to whom proofs should be sent. All other communications should be addressed to the managing editor, or Elaine Barth, University of California, Los Angeles, California, 90024.

50 reprints to each author are provided free for each article, only if page charges have been substantially paid. Additional copies may be obtained at cost in multiples of 50 .

The Pacific Journal of Mathematics is issued monthly as of January 1966. Regular subscription rate: $\$ 102.00$ a year (6 Vols., 12 issues). Special rate: $\$ 51.00$ a year to individual members of supporting institutions.

Subscriptions, orders for numbers issued in the last three calendar years, and changes of address shoud be sent to Pacific Journal of Mathematics, P.O. Box 969, Carmel Valley, CA 93924, U.S.A. Old back numbers obtainable from Kraus Periodicals Co., Route 100, Millwood, NY 10546.

\section{PUBLISHED BY PACIFIC JOURNAL OF MATHEMATICS, A NON-PROFIT CORPORATION}

Printed at Kokusai Bunken Insatsusha (International Academic Printing Co., Ltd.). 8-8, 3-chome, Takadanobaba, Shinjuku-ku, Tokyo 160, Japan. 


\section{Pacific Journal of Mathematics}

\section{Vol. 97, No. $2 \quad$ February, 1981}

Patrick Robert Ahern and N. V. Rao, A note on real orthogonal measures . . . . . 249

Kouhei Asano and Katsuyuki Yoshikawa, On polynomial invariants of fibered

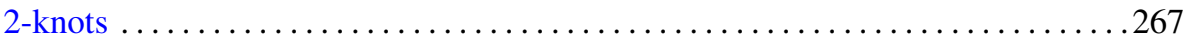

Charles A. Asmuth and Joe Repka, Tensor products for $S L_{2}(\mathscr{K})$. I.

Complementary series and the special representation

Gary Francis Birkenmeier, Baer rings and quasicontinuous rings have a

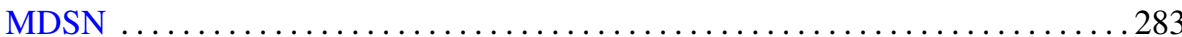

Hans-Heinrich Brungs and Günter Törner, Right chain rings and the generalized

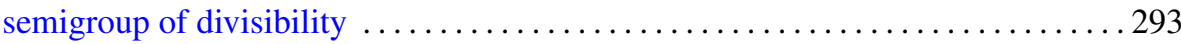

Jia-Arng Chao and Svante Janson, A note on $H^{1} q$-martingales . . . . . . . . . 307

Joseph Eugene Collison, An analogue of Kolmogorov's inequality for a class of

additive arithmetic functions

Frank Rimi DeMeyer, An action of the automorphism group of a commutative ring on its Brauer group

H. P. Dikshit and Anil Kumar, Determination of bounds similar to the Lebesgue

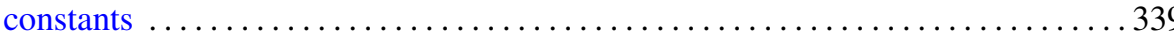

Eric Karel van Douwen, The number of subcontinua of the remainder of the plane

D. W. Dubois, Second note on Artin's solution of Hilbert's 17th problem. Order spaces

Daniel Evans Flath, A comparison of the automorphic representations of GL(3) and its twisted forms

Frederick Michael Goodman, Translation invariant closed $*$ derivations

Richard Grassl, Polynomials in denumerable indeterminates

K. F. Lai, Orders of finite algebraic groups

George Kempf, Torsion divisors on algebraic curves

Arun Kumar and D. P. Sahu, Absolute convergence fields of some triangular matrix methods

Elias Saab, On measurable projections in Banach spaces

Chao-Liang Shen, Automorphisms of dimension groups and the construction of AF algebras

Barry Simon, Pointwise domination of matrices and comparison of $\Phi_{p}$ norms

Chi-Lin Yen, A minimax inequality and its applications to variational inequalities

Stephen D. Cohen, Corrections to: "The Galois group of a polynomial with two indeterminate coefficients"

Phillip Schultz, Correction to: "The typeset and cotypeset of a rank 2 abelian group"

Pavel G. Todorov, Correction to: "New explicit formulas for the $n$th derivative of composite functions"

Douglas S. Bridges, Correction to: "On the isolation of zeroes of an analytic function" 